\title{
Sex related difference in cardiac output during neonatal transition in term neonates
}

\author{
Nariae Baik-Schneditz ${ }^{1,2,3}$, Bernhard Schwaberger ${ }^{1,2,3}$, Lukas Mileder $^{1,2,3}$, Nina Höller ${ }^{1,2,3}$, Alexander Avian ${ }^{4}$, \\ Martin Koestenberger ${ }^{5}$, Berndt Urlesberger ${ }^{1,2,3}$, Johann Martensen ${ }^{1,2,3}$, Gerhard Pichler $^{1,2,3}$ \\ ${ }^{1}$ Division of Neonatology, Department of Paediatrics and Adolescent Medicine, Medical University of Graz, Graz, Austria; ${ }^{2}$ Research Unit for Neonatal \\ Micro- and Macrocirculation, Division of Neonatology, Medical University of Graz, Graz, Austria; ${ }^{3}$ Research Unit for Cerebral Development and \\ Oximetry, Division of Neonatology, Medical University of Graz, Graz, Austria; ${ }^{4}$ Institute for Medical Informatics, Statistics and Documentation, Medical \\ University of Graz, Graz, Austria; ${ }^{5}$ Division of Cardiology, Department of Paediatrics and Adolescent Medicine, Medical University of Graz, Graz, Austria \\ Contributions: (I) Conception and design: N Baik-Schneditz, B Schwaberger, B Urlesberger, G Pichler; (II) Administrative support: A Avian, J \\ Martensen, L Mileder, N Höller, M Koestenberger; (III) Provision of study materials or patients: N Baik-Schneditz, J Martensen, B Schwaberger, N \\ Höller; (IV) Collection and assembly of data: N Baik-Schneditz, J Martensen, A Avian, L Mileder, N Höller; (V) Data analysis and interpretation: N \\ Baik-Schneditz, G Pichler, B Urlesberger, M Koestenberger; (VI) Manuscript writing: All authors; (VII) Final approval of manuscript: All authors. \\ Correspondence to: Gerhard Pichler, MD. Department of Paediatrics and Adolescent Medicine, Medical University of Graz, Auenbruggerplatz 34/2, \\ 8036 Graz, Austria. Email: gerhard.pichler@medunigraz.at.
}

Background: The immediate transition from foetus to neonate includes substantial changes especially concerning the cardiovascular system. As sex related differences have been shown in cardiovascular medicine, this topic warrants further investigation in neonatology. Aim: The aim of this present study was to measure cardiac output (CO) and cerebral oxygenation (cTOI) non-invasively in term neonates and to investigate potential sex related differences between female and male neonates after birth.

Methods: This is a mono-centric prospective observational study. For CO-measurements, the electrical velocimetry method was used. The pulse oximetry for arterial oxygen saturation and heart-rate measurements was placed on the right hand or wrist. cTOI was measured using a NIRO 200NX monitor. The near-infrared spectroscopy probe was positioned on the right side of forehead in each infant. Monitoring started at minute 1 and was continued until minute 15 after birth. At minutes 5, 10, and 15 after birth, CO was calculated as an average out of six 10 -second periods.

Results: 99 term neonates were enrolled. In our study population, we could identify 54 female and 45 male neonates. Males had higher cardiac output compared to females throughout the observational period, with a significant difference in minute 15 after birth (217, 95\% CI: $203-231 \mathrm{~mL} / \mathrm{kg} / \mathrm{min}$ versus $178,95 \%$ CI: 163-192 mL/kg/min; $\mathrm{P}<0.001)$. cTOI, $\mathrm{SpO}_{2}$, and HR did not differ between male and female neonates.

Conclusions: The present work is the first to investigate sex related differences concerning cardiac output in term neonates during postnatal transition, showing a significantly higher cardiac output in male neonates 15 minutes after birth.

Keywords: Cardiac output; term neonates; neonatal transition; sex

Submitted Oct 12, 2020. Accepted for publication Dec 20, 2020.

doi: $10.21037 / \mathrm{cdt}-20-844$

View this article at: http://dx.doi.org/10.21037/cdt-20-844

\section{Introduction}

In the last decade the interest in the period of immediate neonatal transition after birth has been growing. During this vulnerable period of transition from foetus to neonate, complex physiological processes occur affecting all vital organ systems (1). One research focus has been the noninvasive measurement of physiological changes in the cardiovascular system immediately after birth (2-4). 
Centiles for "normal" heart rate with contradictory results $(5,6)$ and blood pressure (7) have been published. The latest guidelines for support of neonatal transition and resuscitation recommended electrocardiography (ECG) and/or pulse oximetry as the only cardiocirculatory monitoring in the delivery room to assess heart rate (8). Yet, monitoring of heart rate alone does not provide comprehensive information about potentially compromised cardio-circulation, which could result in limited oxygen transport to tissue (9). The evaluation of cardiac function as an important parameter of cardio-circulation in the first minutes after birth using echocardiography remains challenging and may not be available in every delivery room. Another possibility to monitor cardiac function and cardiac output are noninvasive cardiac output (CO) measurements (NICOM) using the electrical velocimetry method (10). We recently showed a slight decrease of $\mathrm{CO}$, measured non-invasively in a larger cohort of term neonates immediately after birth in the first minutes after birth (11).

In adult patients, several studies have already demonstrated sex related differences in cardio-circulation (12-14). Sex related differences concerning pathophysiology, clinical features and therapy are more and more in the focus of research, since these differences may have an impact on clinical practice. Sathyaprabha et al. observed a sex related difference in cardiac output measured with thoracic electrical bio-impedance method with men showing higher cardiac output than women (14).

In neonates, there is a well-known sex related difference concerning the outcome of preterm neonates, whereby male preterm neonates have a worse outcome (15). Concerning cardio-circulation, male preterm neonates show a lower blood pressure on the first day after birth, when compared to female preterm neonates (16).

The aim of this study was to analyse cardiac output and cerebral oxygenation in term neonates measured during immediate transition after birth in order to investigate potential sex related differences between male and female neonates. Based on the difference in blood pressure on the first day after birth, we hypothesized that male term neonates would have a lower cardiac output during immediate transition after birth compared to female neonates.

We present the following article in accordance with the MDAR reporting checklist (available at http://dx.doi. org/10.21037/cdt-20-844).

\section{Methods}

Data of a mono-centric prospective observational study conducted in the period from September 2013 to March 2017 at the Division of Neonatology at the Department of Paediatrics and Adolescent Medicine, Medical University of Graz, were analysed.

We included term neonates with a gestational age of $\geq 37$ weeks, fulfilling the following criteria: (I) uncomplicated neonatal transition of 15 minutes, (II) no need for medical support, (III) written informed consent by the parents prior to birth, and (IV) delivery through caesarean section. All infants with major congenital malformation were excluded. We applied the measurements in neonates after caesarean section, because they were routinely observed at the resuscitation table for at least 10 minutes by the neonatologist after caesarean section.

We started a stopwatch, when the baby was delivered. After cord clamping, which was routinely performed after 30 seconds, neonates were taken to the resuscitation table and placed under an overhead heater in supine position. Support of neonatal transition was performed according the recommendations of the latest guidelines $(17,18)$. We applied the arterial oxygen saturation $\left(\mathrm{SpO}_{2}\right)$, heart rate (HR) and cerebral tissue oxygenation index (cTOI) measurements continuously in every infant during the first 15 minutes after birth. For NICOM, the Aesculon monitor (Osypka medical, CA, USA) was used. Before starting the measurement, the skin was cleaned from vernix and the four surface electrodes were placed on the left forehead, left side of the neck, left hemithorax, and left thigh, respectively. The pulse oximetry sensor for $\mathrm{SpO}_{2}$ and $\mathrm{HR}$ measurements was placed on the right hand or wrist. The cTOI was measured using a NIRO 200NX monitor (Hamamatsu, Japan). The near-infrared spectroscopy probe was positioned on the right side of the head in each infant. The sensor on the forehead was secured with cohesive conforming bandage (Peha-haft, Harmann, Heidenheim, Germany).

Monitoring started immediately after birth and was continued until minute 15 . At minutes 5, 10, and 15 after birth, CO was calculated as an average out of six 10 -second periods (with beat-to-beat analysis). The data of these 10 -second periods were only accepted if the Signal quality index (SQI) was $\geq 80 \%$. 
Table 1 Demographic and clinical characteristics of male and female neonates

\begin{tabular}{lccc}
\hline & Male $(\mathrm{n}=45)$ & Female $(\mathrm{n}=54)$ & $\mathrm{P}$ value \\
\hline Gestational age (weeks), mean (SD) & $39.0(38.3-39.3)$ & $38.8(38.4-39.3)$ & $3,235 \pm 467$ \\
Birth weight (g), mean (SD) & $3,369 \pm 515$ & $50[49-52]$ & 0.907 \\
Birth length (cm), mean [SD] & $51[50-53]$ & $34.6 \pm 1.2$ & 0.059 \\
Head circumference (cm), mean (SD) & $35.1 \pm 1.3$ & $10[10-10]$ & 0.064 \\
Apgar score at 5 minutes, median [range] & $10[10-10]$ & $10[10-10]$ & 0.051 \\
Apgar score at 10 minutes, median [range] & $10[10-10]$ & $7.29(7.27-7.30)$ & 0.064 \\
Umbilical artery pH, mean (SD) & $7.29(7.27-7.31)$ & 0.710 \\
\hline
\end{tabular}

All variables were stored using the multichannel system alpha-trace digital MM (BEST Medical Systems, Vienna, Austria) for subsequent analysis. $\mathrm{SpO}_{2}$ and $\mathrm{HR}$ were stored every second, and the sample rate of cTOI was $2 \mathrm{~Hz}$.

The body temperature was not routinely measured in the study group. But the supportive care after birth was given at the neonatal unit, where the surrounding room temperature is kept at a level of around 26 degrees Celsius, whereby this temperature is controlled regularly.

\section{Statistical analysis}

Baseline characteristics are presented as means with standard deviation (SD) for normally distributed continuous variables and medians with interquartile range (IQR) when the distribution was skewed. Categorical variables are given with absolute numbers and percentage. Mean values of cTOI, $\mathrm{SpO}_{2}, \mathrm{HR}$, and $\mathrm{CO}$ were calculated at minutes 5 , 10 , and 15 after birth. To investigate the difference in sex, we divided the study population into two groups: male and female. Group differences in baseline characteristics were analysed, as appropriate, using $\chi^{2}$ and Fisher's exact tests for categorical variables, and Student's t-test or Mann-Whitney $\mathrm{U}$ test for continuous variables. In the main analysis we investigated the changes in cTOI, $\mathrm{SpO}_{2}, \mathrm{HR}$ and $\mathrm{CO} / \mathrm{kg}$ within the first 15 minutes after birth using a linear mixed model with a fixed effect for time (minute 5, 10, and 15) and sex (male. female) using a first-order autoregressive covariance structure. Post hoc analysis were performed to compare groups for each time point. Results according to these linear mixed models are presented using means and $95 \%$ confidence intervals $(95 \% \mathrm{CI})$. A P value $<0.05$ was considered statistically significant. The statistical analyses were performed using IBM SPSS Statistics 26.0.0 (IBM
Corporation; Armonk, USA).

\section{Ethical statement}

The study was conducted in accordance with the Declaration of Helsinki (as revised in 2013). The study was approved by Regional Committee on Biomedical Research Ethics. (EC number 25-342 ex 12/13) and informed consent was taken from all individual participants.

\section{Results}

Finally, we could enrol 99 term neonates. In our study population, we could identify 45 male and 54 female neonates. The demographic data of these two groups are shown in Table 1. We couldn't observe any statistically significant differences concerning demographic data between the groups (Table 1).

We applied the measurements during the process of drying the neonates and the tactile stimulation. As all neonates underwent uncomplicated postnatal transition, we couldn't observe any adverse effect of our measurement.

The courses of vital parameters at 5,10 and 15 minutes after birth of male and female neonates are presented in Table 2. During the whole study period, there was no interferences observed between different devises. All observed parameters except HR showed changes over time (cTOI: $\mathrm{P}<0.001 ; \mathrm{SpO}_{2}$ : $\mathrm{P}<0.001 ; \mathrm{CO} / \mathrm{kg}$ : $\mathrm{P}<0.001$, HR: $\mathrm{P}=0.567)$. Courses of cTOI $(\mathrm{P}=0.728)$ and $\mathrm{SpO}_{2}$ $(\mathrm{P}=0.718)$ where similar between male and female neonates. Furthermore, cTOI values and $\mathrm{SpO}_{2}$ values did not differ between male and female neonates at any time-point. Courses in $\mathrm{CO} / \mathrm{kg}$ differed $(\mathrm{P}<0.001)$. While $\mathrm{CO} / \mathrm{kg}$ where comparable at minute 5 and 10 , at minute 15 male neonates 
Table 2 Courses of vital parameters at 5,10 and 15 minutes after birth of male and female neonates

\begin{tabular}{|c|c|c|c|c|c|c|c|c|c|}
\hline & \multicolumn{3}{|c|}{ Minute 5 after birth } & \multicolumn{3}{|c|}{ Minute 10 after birth } & \multicolumn{3}{|c|}{ Minute 15 after birth } \\
\hline & Male & Female & $P$ value & Male & Female & $P$ value & Male & Female & $P$ value \\
\hline cTOI (\%) & $64.3(61.5-67.1)$ & $63.4(60.8-66.1)$ & 0.661 & $73.1(70.3-75.9)$ & $73.2(70.6-75.7)$ & 0.983 & 72.5 (69.7-75.3) & $73.6(71.0-76.1)$ & 0.576 \\
\hline $\mathrm{SpO}_{2}(\%)$ & $81.3(79.0-83.6)$ & 81.1 (78.8-83.3) & 0.890 & 93.9 (91.6-96.2) & $93.0(90.9-95.2)$ & 0.597 & $95.0(92.7-97.3)$ & 95.3 (93.2-97.5) & 0.835 \\
\hline $\begin{array}{l}\text { HR (beat per } \\
\text { minute) }\end{array}$ & $150.7(145.0-156.3)$ & $153.0(147.6-158.3)$ & 0.557 & $149.8(144.2-155.5)$ & $152.0(146.7-157.3)$ & 0.583 & $152.0(146.4-157.7)$ & 153.5 (148.2-158.8) & 0.707 \\
\hline $\begin{array}{l}\mathrm{CO} \\
(\mathrm{mL} / \mathrm{kg} / \mathrm{min})\end{array}$ & $203(187-218)$ & $196(181-211)$ & 0.535 & $189(175-202)$ & $186(172-200)$ & 0.640 & 217 (203-231) & $178(163-192)$ & $<0.001$ \\
\hline
\end{tabular}

Values are estimated means and $95 \% \mathrm{Cl}$.

had a significant higher $\mathrm{CO} / \mathrm{kg}(\mathrm{P}=0.001)$ compared to female neonates.

\section{Discussion}

This is the first study describing a sex related difference in cardiac output in a larger cohort of term neonates immediately after birth. Male neonates had a statistically significant higher $\mathrm{CO}$ at minute 15 after birth. Furthermore, male neonates tended to have lower heart rates than female neonates, suggesting higher stroke volumes in males than females.

Throughout life, females demonstrate a survival advantage compared to males, suggesting that males are more prone to adverse environmental factors (15). Thus, many study groups focus their research on sex related differences (15,19-22). Naeye et al. reported that male infants have an excessive risk of neonatal death when compared to females. However, it is not yet clear, whether this male disadvantage is due to specific disease processes or a general biologic feature of being male (15). Another study group observed a persisting higher mortality and poorer long-term neurologic outcome in male infants, despite continuously improving neonatal management (19). Concerning intraventricular haemorrhage, very low birth weight male newborn infants are at greater risk to develop brain injury in comparison with their female counterparts (20).

Concerning sex related cardio-circulatory differences, male preterm neonates had lower blood pressure values than females on the first day after birth (16) and extremely preterm males required treatment for arterial hypotension more often during the first week after birth (23). In the present study, we could observe a higher cardiac output in male healthy term neonates undergoing an uncomplicated neonatal transition compared to female neonates.
Interestingly, male neonates tended to have lower heart rates than female neonates.

Sex related differences are mainly due to hereditary differences based on the presence of sex chromosomes (XX for female and XY for males) (24). For cardiovascular conditions, the sex related differences might occur based on the combined expression of hormones and their sex specific sensitivity, which may explain the present findings (24). In adults, sex related CO differences are well described. CO measured non-invasively using the thoracic electrical bio-impedance method in 397 adults (203 men, 194 women) showed higher values in men than in women (14). Adult men usually have higher muscle fraction and are heavier than women, which might be an explanation for these results. While the observation of higher $\mathrm{CO}$ in males is in accordance with our findings, we did not observe a difference in body weight or other demographic data that could explain the differences in $\mathrm{CO}$ immediately after birth.

The exact aetiology of gender specific differences in $\mathrm{CO}$ remains unclear and is likely multifactorial. However, there are sex related differences in the cardiovascular physiology between males and females, which have become evident in the present study. These differences should be recognized and further studies should be performed to optimize clinical care.

\section{Conclusions}

This is the first study to demonstrate a sex related difference in $\mathrm{CO}$ in healthy term neonates during the immediate transition after birth. Male neonates had a higher CO compared to female neonates 15 minutes after birth. This observation contribute that cardio-circulation has sex related differences already immediately after birth in 
healthy term neonates. Further investigations of our group focus on preterm neonates and neonates in need of medical support and resuscitation, where these differences might affect necessary clinical interventions.

\section{Acknowledgments}

We would like to thank the parents for allowing us to study their infants, as well as all the midwives, nurses and physicians involved in the treatment of these neonates.

Funding: None.

\section{Footnote}

Reporting Checklist: The authors have completed the MDAR reporting checklist. Available at http://dx.doi.org/10.21037/ cdt-20-844

Data Sharing Statement: Available at http://dx.doi. org/10.21037/cdt-20-844

Peer Review File: Available at http://dx.doi.org/10.21037/ cdt-20-844

Conflicts of Interest: All authors have completed the ICMJE uniform disclosure form (available at http://dx.doi. org/10.21037/cdt-20-844). The authors have no conflicts of interest to declare.

Ethical Statement: The authors are accountable for all aspects of the work in ensuring that questions related to the accuracy or integrity of any part of the work are appropriately investigated and resolved. The study was conducted in accordance with the Declaration of Helsinki (as revised in 2013). The study was approved by Regional Committee on Biomedical Research Ethics. (EC number 25-342 ex 12/13) and informed consent was taken from all individual participants.

Open Access Statement: This is an Open Access article distributed in accordance with the Creative Commons Attribution-NonCommercial-NoDerivs 4.0 International License (CC BY-NC-ND 4.0), which permits the noncommercial replication and distribution of the article with the strict proviso that no changes or edits are made and the original work is properly cited (including links to both the formal publication through the relevant DOI and the license). See: https://creativecommons.org/ licenses/by-nc-nd/4.0/.

\section{References}

1. Rudolph AM. Fetal and neonatal pulmonary circulation. Annu Rev Physiol 1979;41:383-95.

2. Noori S, Stavroudis TA, Seri I. Systemic and cerebral hemodynamics during the transitional period after premature birth. Clin Perinatol 2009;36:723-36, v.

3. van Vonderen JJ, te Pas AB, Kolster-Bijdevaate C, et al. Non-invasive measurements of ductus arteriosus flow directly after birth. Arch Dis Child Fetal Neonatal Ed 2014;99:F408-12.

4. Schwaberger B, Pichler G, Binder-Heschl C, et al. Transitional Changes in Cerebral Blood Volume at Birth. Neonatology 2015;108:253-8.

5. Dawson JA, Morley CJ. Monitoring oxygen saturation and heart rate in the early neonatal period. Semin Fetal Neonatal Med 2010;15:203-7.

6. van Vonderen JJ, Roest AA, Siew ML, et al. Noninvasive measurements of hemodynamic transition directly after birth. Pediatr Res 2014;75:448-52.

7. Pichler G, Cheung PY, Binder C, et al. Time course study of blood pressure in term and preterm infants immediately after birth. PLoS One 2014;9:e114504.

8. Wyllie J, Bruinenberg J, Roehr CC, et al. European Resuscitation Council Guidelines for Resuscitation 2015: Section 7. Resuscitation and support of transition of babies at birth. Resuscitation 2015;95:249-63.

9. Baik N, Urlesberger B, Schwaberger B, et al. Cardiocirculatory monitoring during immediate fetal-toneonatal transition: a systematic qualitative review of the literature. Neonatology 2015;107:100-7.

10. Noori S, Drabu B, Soleymani S, et al. Continuous non-invasive cardiac output measurements in the neonate by electrical velocimetry: a comparison with echocardiography. Arch Dis Child Fetal Neonatal Ed 2012;97:F340-3.

11. Freidl T, Baik N, Pichler G, et al. Haemodynamic Transition after Birth: A New Tool for Non-Invasive Cardiac Output Monitoring. Neonatology 2017;111:55-60.

12. Joyner MJ, Wallin BG, Charkoudian N. Sex differences and blood pressure regulation in humans. Exp Physiol 2016;101:349-55.

13. Marra AM, Salzano A, Arcopinto M, et al. The impact of gender in cardiovascular medicine: Lessons from the gender/sex-issue in heart failure. Monaldi Arch Chest Dis 2018;88:988. 
14. Sathyaprabha TN, Pradhan C, Rashmi G, et al. Noninvasive cardiac output measurement by transthoracic electrical bioimpedence: influence of age and gender. J Clin Monit Comput 2008;22:401-8.

15. Naeye RL, Burt LS, Wright DL, et al. Neonatal mortality, the male disadvantage. Pediatrics 1971;48:902-6.

16. Laughon M, Bose C, Allred E, et al. Factors associated with treatment for hypotension in extremely low gestational age newborns during the first postnatal week. Pediatrics 2007;119:273-80.

17. Wyckoff MH, Aziz K, Escobedo MB, et al. Part 13: Neonatal Resuscitation: 2015 American Heart Association Guidelines Update for Cardiopulmonary Resuscitation and Emergency Cardiovascular Care. Circulation 2015;132:S543-60.

18. Kattwinkel J, Perlman JM, Aziz K, et al. Part 15: neonatal resuscitation: 2010 American Heart Association Guidelines for Cardiopulmonary Resuscitation and Emergency Cardiovascular Care. Circulation 2010;122:S909-19.

19. Kent AL, Wright IM, Abdel-Latif ME, New South Wales and Australian Capital Territory Neonatal Intensive Care Units Audit Group. Mortality and adverse neurologic outcomes are greater in preterm male infants. Pediatrics 2012;129:124-31.

20. Mohamed MA, Aly H. Male gender is associated with intraventricular hemorrhage. Pediatrics 2010;125:e333-9.

21. O'Driscoll DN, Greene CM, Molloy EJ. Immune function? A missing link in the gender disparity in preterm neonatal outcomes. Expert Rev Clin Immunol 2017;13:1061-71.

22. O'Driscoll DN, McGovern M, Greene CM, et al. Gender disparities in preterm neonatal outcomes. Acta Paediatr 2018. [Epub ahead of print]. doi: 10.1111/apa.14390.

23. Razzaq A, Iqbal Quddusi A, Nizami N. Risk factors and mortality among newborns with persistent pulmonary hypertension. Pak J Med Sci 2013;29:1099-104.

24. Shufelt CL, Pacheco C, Tweet MS, et al. Sex-Specific Physiology and Cardiovascular Disease. Adv Exp Med Biol 2018;1065:433-54.

Cite this article as: Baik-Schneditz N, Schwaberger B, Mileder L, Höller N, Avian A, Koestenberger M, Urlesberger B, Martensen J, Pichle G. Sex related difference in cardiac output during neonatal transition in term neonates. Cardiovasc Diagn Ther 2021;11(2):342-347. doi: 10.21037/cdt-20-844 